\title{
Nutritional status of under-five children in urban slums of Pune
}

Megha S. Mamulwar, Hetal K. Rathod, Sumit Jethani, Anjali Dhone, Tanu Bakshi, Balkrishna Lanjewar, Sudhir Jadhav, Jitendra S. Bhawalkar

Department of Community Medicine, Pad Dr. D Y Patil Medical College, Pune, Maharashtra, India

Address for Correspondence: Dr. Megha S. Mamulwar, Department of community Medicine, Pad Dr. D Y Patil Medical College, Pune - 411 018, Maharashtra, India. E-mail: megha.antwal@gmail.com

\begin{tabular}{|l|}
\hline Access this article online \\
\hline Website: www.ijmedph.org \\
\hline DOI: $10.4103 / 2230-8598.137710$ \\
\hline Quick response code: \\
\hline
\end{tabular}

Background: The nutritional status of under five children in urban slums is an important health indicator for assessing the health status of entire population and one of the major predictors of child survival. Objective: A nutritional survey was carried out in September- October 2012 in the field practice area of a medical college in Pimpri, Pune area with an objective to assess the nutritional status of under-five children. Materials and Methods: All the under five students in the field practice area of the medical college were examined. A total of 658 children were examined. Results and Conclusion: It was observed that the prevalence of under weight $34.3 \%$ (226/654) (30.7 to 38.0 C.I.), stunting $58.7 \%$ (386/654) (54.9 to 62.4 C.I.) and wasting was $16.9 \%(109 / 654)(14.0$ to $19.795 \%$ C.I.). The prevalence of under weight $37.6 \%(114 / 303)$ and stunting $61.4 \%(186 / 303)$ was more in girls whereas wasting was more in boys $18 \% .(64 / 355)$

Key words: Malnutrition, under-five, urban slums

\section{INTRODUCTION}

Nutritional status of under five children is a matter of concern worldwide and malnutrition is a one of the most important public health problems. Globally, one quarter of under five children are stunted (estimated 162 million). South Asia particularly has a high prevalence of stunting (38\%), underweight $(32 \%)$ and alarmingly high percentage of wasting $(16 \%)$ as compared to other regions in the world. ${ }^{[1]}$ As per National Family Health Survey III, 48\% children in India are stunted, 43\% wasted and nearly $20 \%$ are under weight. Maharashtra state is performing better in terms of stunting (46.3\%) and wasting $(16.5 \%)$, but the percentage of under weight children is higher $(37 \%)$ as compared to national level statistics. ${ }^{[2]}$

The Pimpri Chinchwad Municipal Corporation is one of the rich municipal corporations in South East Asia due to large number of automobile and software industry located in the nearby area. ${ }^{[3]}$ This industrialisation of the Pimpri Chinchwad Municipal Corporation has also led to rapid development of slums due to the workers who get employed in these industries. The nutritional status of under-five children in these slums is very important because this is a vulnerable group which may fall prey to different types of communicable diseases that can spread easily due to high population density, poor hygiene, illiteracy and poor socioeconomic status in these areas. Malnutrition is not a single problem with a single solution. Multiple and interrelated determinants are responsible for under nutrition. ${ }^{[4]}$

Malnutrition in under-five children can be easily assessed by measurement of height and weight. With release of WHO child growth standards in 2006 the trajectory of malnutrition can be studied in terms of weight for age (underweight), height for age (stunting) and weight for height (wasting)..$^{[5]}$ The Lancet series on maternal and child health has emphasized and promoted the use these anthropometric parameters for assessing nutritional status of under five children. ${ }^{[6-8]}$ Hence, with an aim to assess the nutritional status of under five children in the slums of Pune this study was planned.

\section{MATERIALS AND METHODS}

A total of 658 children were examined in field practice area during September-October 2012. All the children who were more than five years of age were excluded from this study. Informed consent of the parents of under five children was obtained before under taking the study. The data was collected 
using a pretested questionnaire. Age of the child and vaccination status was confirmed using the hospital records and immunization card whenever available. These details were confirmed from a reliable informant when these records were unavailable. An attempt was also made to take the history of any major illness in last 6 months.

\section{Anthropometry}

All children were divided in small groups and anthropometric measurements were taken using standardised equipments. Length of children up to the age of two years was measured with the child on horizontal measuring scale. Height of children above 2 year of age was measured by the child standing on a horizontal surface against a vertical measuring scale. Standing height was measured up to nearest of $0.1 \mathrm{~cm}$. The child was made to stand against the scale without shoes, heels together and shoulder, buttocks and heels touching the vertical surface. Height was recorded with a head piece touching the top of the head when child was looking straight and arms hanging by the sides in a natural manner. Weight was recorded on a salter type of portable weighting machine up to nearest $0.1 \mathrm{~kg}$ for children less than two years with minimal clothes. Children more than two year were weighed with minimal clothes and bare feet with a weighing machine (beam type) pretested for accuracy. ${ }^{[9]}$ Mean of three different readings was taken as final weight of the child.

\section{Statistical analysis}

Data collected was entered in Microsoft excel. Confidence interval, Chi square and Chi square for trend were calculated to analyse data using SPSS 18, Quarry Bay, Hong Kong, China. Emergency Nutrition Assessment software, Ireland was used to analyse anthropometric data, to calculate the $\mathrm{Z}$ score, analysis of scores and generating growth curves. ${ }^{[10]}$ The WHO standards were used for comparing the data. Analysing the data using this software and then comparing it with WHO growth curves was a novel experience.

Operational Definitions for categorising the malnutrition according to Z score. ${ }^{[5]}$

(<-2 z-score) Global Acute Malnutrition (wasting)/Underweight / Stunting

( $<-2$ z-score and $>=-3$ z-score) Moderate Acute Malnutrition (wasting)/Underweight / Stunting

(<-3 z-score) Severe Acute Malnutrition (wasting)/Underweight/ Stunting

Each anthropometric indicator has a different meaning, hence to get a comprehensive picture of a child's nutritional status, it would be important to derive all three nutrition indices.

\section{RESULTS}

There were 658 children who were examined in the study out of which $53.7 \%$ (355/ 658) were boys and 46.3\% (303/658) were girls. The mean age of the children in the study was 28.9 months (SD 15.6).
The age and sex wise distribution of students is given in Table 1.

Most of the children examined in the study belongs to the age group of 13 to 36 months. The child sex ratio of the study group was 1.2. The mean birth weight of the children was $2.7 \mathrm{~kg}$ ( $\mathrm{n}=538)$. There was no significant difference in the mean height and weight of male (Mean weight $=10.4 \mathrm{~kg}$ Mean height $=80.09 \mathrm{~cm})$ and female $($ Mean weight $=10.3 \mathrm{~kg}$ Mean height $=81.3 \mathrm{~cm}$ ) children in the study. Mean weight and height for the age group of 1 to12 months and 37 to 60 months was $7.1 \mathrm{~kg}, 65.3 \mathrm{~cm}$ and $12.9 \mathrm{~kg}, 93.5 \mathrm{~cm}$ respectively.

Figure 1 shows the comparison of anthropometric parameters with WHO growth standards as weight for age, height for age and weight for height.

\section{Weight for age (under weight) $(n=658)$}

The prevalence of low weight for age, i.e. underweight was $34.3 \%$ (226/ 658) (30.7 to 38.0 C.I.) with girls being more underweight $37.6 \%(114 / 303)$ (32.2 to 43.1 C.I.) as compared to boys $31.5 \%$ (112/355) (26.7 to 36.4 C.I.). Prevalence of moderate acute malnutrition, based on weight for age $\mathrm{Z}$ score (under weight) was $22.5 \%$ (148/658) (19.3 to 25.7 C.I.) with marginal difference between boys $21.7 \%$ (77/355) and girls 23.4\% (71/303). Prevalence of severe acute malnutrition was $11.9 \%$ (78/658) (9.4-14.3 C.I.). The prevalence of severe malnutrition using weight for age $\mathrm{Z}$ score was more among girls $14.2 \%$ (43/303) (10.3 to 18.1 C.I.) as compared to boys $9.9 \%$ ( $35 / 355)$ ( 6.8 to 13.0 C.I.).

\begin{tabular}{|c|c|c|c|c|c|c|c|}
\hline \multirow{2}{*}{$\begin{array}{l}\text { Age } \\
\text { (months) }\end{array}$} & \multicolumn{2}{|c|}{ Male } & \multicolumn{2}{|c|}{ Female } & \multicolumn{2}{|c|}{ Total } & \multirow{2}{*}{$\begin{array}{c}\text { Ratio } \\
\text { Male : Female }\end{array}$} \\
\hline & no. & $\%$ & no. & $\%$ & no. & $\%$ & \\
\hline $1-12$ months* & 74 & 56.9 & 56 & 43.1 & 130 & 19.9 & 1.3 \\
\hline $13-36$ months & 197 & 56.4 & 152 & 43.6 & 349 & 53.4 & 1.3 \\
\hline $37-60$ months & 80 & 45.7 & 95 & 54.3 & 175 & 26.8 & 0.8 \\
\hline Total & 351 & 53.7 & 303 & 46.3 & 654 & 100.0 & 1.2 \\
\hline
\end{tabular}

$*_{0-1}$ month age group was excluded because there were only four children in this category

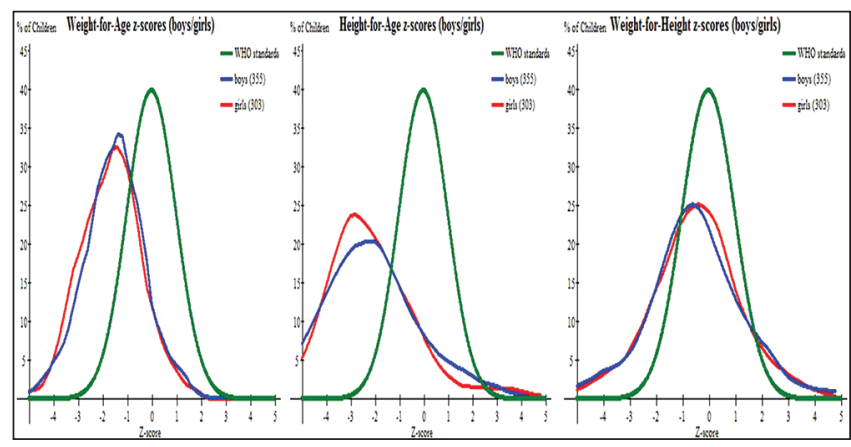

Figure 1: Comparison of anthropometric parameters with WHO growth standards (The graph shows the comparison of weight for age, height for age and weight for height $Z$ scores of children (boys and girls) included in the study with the WHO growth curves generated using the Emergency Nutrition Assessment software. $(n=658)$ 


\section{Height for age (stunting) $(n=658)$}

The prevalence of low height for age, i.e. stunting is $58.7 \%$ (386/658) (54.9-62.4 C.I.). It was observed that girls were more stunted $61.4 \%(186 / 303)$ (55.9-66.9 C.I.) as compared to boys $56.3 \%$ (200/355) (51.2 to 61.5 C.I.). Prevalence of moderate stunting was $24 \%(158 / 658)$ (20.7 to 27.3C.I.) with boys being $23.4 \%(83 / 355)$ and girls $24.8 \%(75 / 303)$ stunted. Prevalence of severe stunting was $34.7 \%$ (228/658) (31.0-38.3 C.I.) with severe stunting being more commonly seen among girls $36.6 \%$ (111/303) (31.2-42.1 C.I.) as compared to boys 33.0\% (117/355) (28.1-37.8 C.I.).

\section{Weight for Height (Wasting) $(\mathrm{n}=\mathbf{6 5 8})$}

The prevalence of wasting was 16.9\% (111/658) (14.0 - $19.795 \%$ C.I.). It was seen that in general boys were more wasted as compared to girls especially the prevalence of severe wasting was very high $(8.7 \%)(31 / 355)$ among boys than girls (6.6\%) (20/303).

Table 2 shows severely underweight children were more in 37 to $-60(15.4 \%)(27 / 175)$ age group whereas severe stunting was high in 1 to 12 months and 37 to 60 months age group. The proportion of sever and moderately underweight children was found to increase with advancing age of the child.

The percentage of children who were found to have severe wasting was more $(12.3 \%)(16 / 130)$ in 1 to 12 months age group as compared to higher age groups i.e. 13 to -36 months and 37 to 60 months. The moderate wasting was seen to increase with advancing age of the child.

Table 3 shows that low birth weight babies tend to remain malnourished as compared with their counter parts who have normal

\begin{tabular}{|c|c|c|c|c|c|c|c|c|c|}
\hline \multirow{2}{*}{$\begin{array}{l}\text { Age } \\
\text { (mths) }\end{array}$} & \multicolumn{3}{|c|}{ Weight for age (Underweight) $(n=654)$} & \multicolumn{3}{|c|}{ Height for age (Stunting) $(n=654)$} & \multicolumn{3}{|c|}{ Weight for height (Wasting) ( $n=654$ ) } \\
\hline & $\begin{array}{c}\text { Severe } \\
\text { under-weight }\end{array}$ & $\begin{array}{c}\text { Moderate } \\
\text { under-weight }\end{array}$ & Normal & $\begin{array}{c}\text { Severe } \\
\text { stunting }\end{array}$ & $\begin{array}{c}\text { Moderate } \\
\text { stunting }\end{array}$ & Normal & $\begin{array}{c}\text { Severe } \\
\text { wasting }\end{array}$ & $\begin{array}{c}\text { Moderate } \\
\text { wasting }\end{array}$ & Normal \\
\hline $1-12$ & $14(10.8)$ & $26(20.0)$ & $90(69.2)$ & $48(36.9)$ & $21(16.2)$ & $61(46.9)$ & $16(12.3)$ & $4(3.1)$ & $110(84.6)$ \\
\hline $13-36$ & $37(10.6)$ & $71(20.3)$ & $241(69.1)$ & $118(33.8)$ & $99(28.4)$ & $132(37.8)$ & $22(6.3)$ & $32(9.2)$ & $295(84.5)$ \\
\hline $37-60$ & $27(15.4)$ & $51(29.1)$ & $97(55.4)$ & $63(36.0)$ & $37(21.1)$ & 75 (42.9) & $11(6.3)$ & $24(13.7)$ & $140(80.0)$ \\
\hline \multirow[t]{3}{*}{ Total } & $78(11.9)$ & $148(22.6)$ & $428(65.4)$ & $229(35.0)$ & $157(24.0)$ & $268(41.0)$ & $49(7.5)$ & $60(9.2)$ & $545(83.3)$ \\
\hline & $226(34.3)$ & & & $386(58.7)$ & & & $109(16.9)$ & & \\
\hline & $P=0.03$ & & & $P=0.05$ & & & $P=0.006$ & & \\
\hline
\end{tabular}

\begin{tabular}{|c|c|c|c|c|c|c|c|c|}
\hline \multirow[t]{3}{*}{ Age (months) } & \multicolumn{8}{|c|}{ Birth weight $n=538$ as data for 120 was missing } \\
\hline & \multicolumn{2}{|c|}{ Weight for age (under weight) } & \multicolumn{3}{|c|}{ Height for age (Stunting) } & \multicolumn{3}{|c|}{ Weight for height (Wasting) } \\
\hline & SAM MAM & NORMAL & SAM & MAM & NORMAL & SAM & MAM & NORMAL \\
\hline$\leq 2.5 \mathrm{~kg}$ & $43(16.2)^{\#} 77(29.1)$ & $145(54.7)$ & $116(43.8)$ & $69(26)$ & $80(30.2)$ & $17(6.4)$ & $27(10.2)$ & $221(83.4)$ \\
\hline$>2.5 \mathrm{~kg}$ & $19(7.0) \quad 45(16.5)$ & $209(76.6)$ & $77(28.2)$ & $61(22.3)$ & $135(49.5)$ & $21(7.7)$ & $19(7)$ & $233(85.3)$ \\
\hline \multirow[t]{3}{*}{ Total } & $62(11.5) \quad 122(22.7)$ & $354(65.8)$ & $193(35.9)$ & $130(24.2)$ & $215(40.0)$ & $38(7.1)$ & $46(8.6)$ & $454(84.4)$ \\
\hline & \multicolumn{2}{|c|}{$X^{2}=29.1 P=<0.001$} & \multicolumn{3}{|c|}{$X^{2}=22.3 P=<0.001$} & \multicolumn{3}{|c|}{$X^{2}=2.0 P=<0.37$} \\
\hline & \multicolumn{8}{|c|}{ Type of family $n=635$, as data for 23 children was not available } \\
\hline Nuclear & $63(19.8)$ & $217(68.2)$ & $108(34.0)$ & $64(20.1)$ & $146(45.9)$ & $27(8.5)$ & $25(7.9)$ & $266(83.6)$ \\
\hline Joint & $69(24.0)$ & $183(63.5)$ & $100(34.7)$ & $75(26.0)$ & $113(39.2)$ & $23(8.0)$ & $28(9.7)$ & $237(82.3)$ \\
\hline Separated & $1(3.4) \quad 9(31.0)$ & $19(65.5)$ & $11(37.9)$ & $13(44.8)$ & $5(17.2)$ & 0 & $1(3.4)$ & $28(96.6)$ \\
\hline \multirow[t]{3}{*}{ Total } & $75(11.8) \quad 141(22.2)$ & $419(66)$. & $219(34.5)$ & $152(23.9)$ & $264(41.6)$ & $50(7.9)$ & $54(8.5)$ & $531(83.6)$ \\
\hline & \multicolumn{2}{|c|}{$X^{2}=5.549 ., P=0.476$} & \multicolumn{3}{|c|}{$\mathrm{X}^{2}=13.828, P=0.008$} & \multicolumn{3}{|c|}{ ** } \\
\hline & \multicolumn{8}{|c|}{ Education of mother $n=556$, as data for 102 children was not available } \\
\hline Illiterate and primary & $11(18.6)$ & $40(67.8)$ & $23(39.0)$ & $14(23.7)$ & $22(37.3)$ & $3(5.1)$ & $4(6.8)$ & $52(88.1)$ \\
\hline Secondary & $84(21.9)$ & $250(65.1)$ & $134(34.9)$ & $91(23.7)$ & $159(41.4)$ & $27(7.0)$ & $35(9.1)$ & $322(83.9)$ \\
\hline Higher secondary and above & $28(24.8)$ & $74(65.5)$ & $41(36.3)$ & $25(22.1)$ & $47(41.6)$ & $12(10.6)$ & $10(8.8)$ & $91(80.5)$ \\
\hline \multirow[t]{3}{*}{ Total } & $69(12.4) \quad 123(22.1)$ & $364(65.5)$ & $198(35.6)$ & $130(23.4)$ & $228(41.0)$ & $42(7.6)$ & $49(8.8)$ & $465(83.6)$ \\
\hline & \multicolumn{2}{|c|}{$X^{2}=1.6, P=0.812$} & \multicolumn{3}{|c|}{$X^{2}=0.6, P=0.9$} & \multicolumn{3}{|c|}{$X^{2}=2.6, P=0.6$} \\
\hline & \multicolumn{8}{|c|}{ Birth order $n=658$} \\
\hline 1 & $25(9.9) \quad 53(20.9)$ & $175(69.2)$ & $80(31.6)$ & $77(30.4)$ & $96(37.9)$ & $16(6.3)$ & $19(7.5)$ & $218(86.2)$ \\
\hline 2 & $28(13.9) \quad 43(21.3)$ & $131(64.9)$ & $76(37.6)$ & $36(17.8)$ & $90(44.6)$ & $21(10.4)$ & $19(9.4)$ & $162(80.2)$ \\
\hline$\geq 3$ & $25(12.3) \quad 52(25.6)$ & $126(62.1)$ & $73(36.0)$ & $44(21.7)$ & $86(42.4)$ & $14(6.9)$ & $22(10.8)$ & $167(82.3)$ \\
\hline \multirow[t]{2}{*}{ Total } & 78 (11.9) $148(22.5)$ & $432(65.7)$ & $229(34.8)$ & $157(23.9)$ & $272(41.3)$ & $51(7.8)$ & $60(9.1)$ & $547(83.1)$ \\
\hline & \multicolumn{2}{|c|}{$X^{2}=3.7, P=0.4$} & \multicolumn{3}{|c|}{$X^{2}=10.6, P=0.03$} & \multicolumn{3}{|c|}{$X^{2}=4.6, P=0.3$} \\
\hline
\end{tabular}

\#fig in parenthesis are percentages, SAM ${ }^{\# \# S e v e r e ~ a c u t e ~ m a l n u t r i t i o n, ~ M A M " \# \# ~ M o d e r a t e ~ a c u t e ~ m a l n u t r i t i o n, ~ * * s t a t i s t i c a l ~ t e s t ~ c o u l d ~ n o t ~ b e ~ a p p l i e d ~ a s ~}>20 \%$ cells have expected count less than 5 
birth weight. In this study, it was observed that children belonging to separated families are more likely to be malnourished as compared to children from joint and nuclear families. With increasing years of schooling in mothers the nutritional status of children improves except for the category of height for age where there was a marginal increase in cases of severe malnutrition. But this was not statistically significant. Children with higher birth order $\left(2^{\text {nd }}\right.$ and $\left.\geq 3^{\text {rd }}\right)$ were more likely to be malnourished (underweight, stunted/wasted) as compared with first born child and the distribution was found to be statistically significant in stunting.

\section{Children's morbidity}

There were 70 children who had ARI, 14 children had diarrhoea, 18 children had only fever, 4 children with exanthematous fever and very few cases of chronic diseases like ARF, Asthma, Thalassemia etc six months prior to study.

\section{Vaccination status}

There were $2.9 \%$ (19/658) children out of 658 whose immunisation was incomplete. No statistical association could be observed between the current nutritional status and immunisation.

\section{Breast feeding initiation}

There were $82.8 \%$ (545/658) children for whom breast feeding was initiated within first three hours of delivery and for $10.3 \%$ (68/658) children BF was initiated within 1-3 days of delivery and remaining 45 children were started BF after 3 days of delivery. No statistical association could be proved between the current nutritional status and time required for initiation of breast feeding.

\section{DISCUSSION}

The present study was conducted in urban field practice area of a Medical college. The study was analyzed by WHO child growth standards obtained by multicentric growth reference study. The new WHO standards (2006) depict normal early childhood growth under optimal environmental condition and used to assess children everywhere, regardless of ethnicity, socioeconomic status and type of feeding. ${ }^{[1]}$

Total 658 children were in the study out of which 355 were boys and 303 were girls. The mean age of the children who were included in the study was 28.9 months (SD 15.6). Most of the children examined in the study were in the age group of 13 to 36 months. The child sex ratio in this study for 37 to 60 months category was 0.8 , there was a slight decline in the child sex ratio to 1.3 for 1 to 12 months and 13 to 36 months category and this trend i.e. decreasing child sex ratio is comparable to the national statistics. ${ }^{[12]}$

The mean birth weight of the children noted in this study is similar to the one found in slums of Mumbai $(2.7 \mathrm{~kg}),{ }^{[13]}$ where as the mean height and weight of girls and boys was higher than the similar study carried out in Bagalkot. ${ }^{[11]}$
Graphical representation of the anthropometric parameters when compared gender-wise with the WHO standards showed that the Proportion of stunted girls was more as compared to boys. There is a leftward shift in case of means of all three anthropometric parameters compared to WHO Z score curve but is more obviously seen in means of $\mathrm{Z}$ scores of height for age (right/positive skew).

\section{Underweight}

The percentage of children who were underweight $(34.3 \%)$ $(226 / 654)$ is less as compared to the national level statistics as per National Family Health Survey $3^{[2]}$ and similar studies carried out in other parts of the country (Mumbai 35\%, Bagalkot 65.4\%) ) $^{[11,13]}$ There are few places like Ludhiana (29.5\%) and West Bengal (28.6\%) where the prevalence of underweight children is lower as compared to the present study. ${ }^{[14,15]}$

\section{Stunting}

National prevalence of stunting as observed in the National Family Health Survey 3 conducted in 2005 to 2006 was $51.7 \%$ which is slightly lower than this study $(58.7 \%)(386 / 658) .{ }^{[2]}$ Similar studies conducted in Mumbai (47\%), Punjab (16.7\%) and Qatar (4.4\%) noted lower prevalence of stunting as compared to the present study. ${ }^{[13,16,17]}$ Prevalence of stunting was found to be more in girls as compared to boys which is in contrast to the findings of NFHS 3 (Male 48.1\%, Female 48\%). ${ }^{[2]}$ Stunting was the predominant growth faltering, as observed in studies carried out in Bagalkot $(72.7 \%)$, Ludhiana (74\%), West Bengal (50.9\%) and Kerala (61\%). ${ }^{[11,14,15,18]}$

\section{Wasting}

The prevalence of wasting as noted in this study (16.9\%) (109/654) was comparable with national and state level NFHS 3 data $^{[2]}$ and also with similar studies carried out in other parts of the country like Mumbai (17\%). ${ }^{[13]}$ Studies carried out in Bagalkot (32.5\%) and Ludhiana $(42 \%)$ revealed a high prevalence of wasting. ${ }^{[11,14]}$

The age wise trends in malnutrition in terms of all three anthropometric parameters (under weight, stunting and wasting) as given Table 2 , it is evident that the nutritional status of children deteriorates progressively through the first three years of life and stunting is the predominant type of malnutrition seen; however wasting was not that common. Children who were born as low birth weight were found to be more stunted and underweight; wasting was not that prevalent in them also. A similar finding was noted in the study carried out in slums of Mumbai ${ }^{[13]}$ and has reiterated the fact that wasting is not as big problem as stunting and children follow a stunted trajectory established early in life. As our study shows that weight for height i.e. wasting is less compared to other nutritional parameters which is related to the recent hypothesis 'small but healthy' and is yet to receive any sort of scientific support. ${ }^{[19]}$

The WHO multicentric study (Indian component of study sample from well of families in South Delhi) on growth reference found no evidence of Indian children being genetically shorter than other 
children, ${ }^{[5]}$ whereas; our study comprises of slum children where factors like intergenerational nutritional influence, environmental factors have an impact on the anthropometric parameters of children. This may be due to improper weaning and recurrent infections commonly seen in this age group. Thus appropriate feeding and weaning process has to be introduced in the population by appropriate parental health education to improve the nutritional status of under five children as has been proved in various studies conducted across the world. ${ }^{[20,21]}$ This period is the critical window of opportunity to prevent under nutrition from before pregnancy to the first two years of life. Therefore, the first 1000 days comprising the prenatal period and the first two years of life are crucial to make a lifelong lasting difference by breaking the intergenerational cycle of under nutrition. Once these 1000 days are over this 'window of opportunity' closes for life. ${ }^{[22]}$

Prevalence of underweight and stunting was significantly more in children belonging to separated families as compared with children belonging to nuclear families as they may not be fed properly.

Limiting the family size to 2 can be considered as an important intervention to improve the nutritional status of children as children with higher birth order are more likely to be malnourished which is comparable to another study carried out in slums of Pune. ${ }^{[23]}$

\section{Mother's education}

As the education of mother increases- all three anthropometric parameters of their children were found to be improving, but the statistical association could not be proved in this study, similar findings were seen in studies carried out in Ludhiana and Kerala. ${ }^{[14,18]}$ However mother's education remains an important factor influencing child's nutritional status as seen in various other studies conducted across the country. ${ }^{[24-27]}$

\section{Recommendations}

The families from the community should be encouraged for home based activities to improve the nutritional status of children.

\section{Future nutrition monitoring}

Severely malnourished children should be surveyed on regular basis and home visits should be given.

Parents of the malnourished children should be counselled for nutritious diet, importance of family planning and personal hygiene by the experts at the time of home visits.

A qualitative study in the form of in-depth interview and focused group discussion among parents of malnourished children should be carried out to study the causes of malnutrition in details and to find out the various measures to correct malnutrition.

\section{LIMITATIONS}

The causes of malnutrition could not be assessed in this study as this was a rapid survey to find out the prevalence of different forms of malnutrition. Association of malnutrition with only few sociodemographic factors were studied.

\section{ACKNOWLEDGEMENTS}

Authors will like to acknowledge local anganwadis, Resident Medical Officers (Dr. Archana Pandge, Dr. Jayant Kalkute, Dr. Abhishek Mahajan, Dr. Madhur Raimule) Departmental and UHTC staff for their field support.

\section{REFERENCES}

1. Monitoring the Situation of children and women, Unicef. Available from: http://www.childinfo.org/malnutrition_status.html [Last accessed on 2013 Dec 13].

2. International Institute of Population Sciences (IIPS) and Macro International. 2007 National Family Health Survey (NFHS- 3) 20052006)।: India: 1 Mumbai IIPS.:273.

3. One on One, After years of plenty, some belt-tightening. Oct 8, 2001, 12.45am IST. Available from: http://www.articles.timesofindia.indiatimes. com/2001-10-08/pune/27234652_1_octroi-revenue-octroi-income-pcmc [Last accessed on 2013 Dec 19].

4. United Nation Children Fund. The state of world's children. United Kingdom: Oxford University Press; 1998.

5. WHO (2006), WHO Child Growth Standars, Length/height for age, Weight for age, Weight for length, Weight for height, Body mass index, for age, Methods and development. Available from: http://www.who.int/ childgrowth/en [Last accessed on 2013 Dec 10].

6. Black RE, Allen LH, Bhutta ZA, Caulfield LE, de Onis M, Ezzati M, et al. Maternal and child under nutrition: Global and regional exposures and health consequences. Lancet 2008;371:243-60.

7. Victora CG, Adair L, Fall C, Hallal PC, Martorell R, Richter L, et al. Maternal and Child Under nutrition: Consequences for adult health and human capital. Lancet 2008;371:340-57

8. Bhutta ZA, Ahmed T, Black RE, Cousens S, Dewey K, Giugliani E, et al. For the maternal and child under nutrition study group. What works? Interventions for maternal and child under nutrition and survival. Lancet 2008;371:417-40.

9. Module 6 Measuring Malnutrition Individual Assessment Technical Notes. HTP, Version 2, 2011. Available form: http://www.unicef.org/nutritioncluster /files/Module6MeasuringMalnutritionIndividualAssessmentTechnicalNotes. pdf [Last accessed on 2013 Dec 12].

10. Emergency Nutrition Assessment software. Available from: http://www. nutrisurvey.de/ena/ena.html [Last accessed on 2013 Aug 28].

11. Badami SV, Diwanji S, Vijaykrishna K, Bhandarkar N, Chinagudi S, Herur A, et al. Nutritonal Status of belowfive children in urban slums of Bagalkot. Med Innov 2012;1:28-34.

12. Children in India 2012- A statistical appraisal, Social Statistics Division, Central Statistics Office, Ministry of statistics and programme Implementation, Govt of India. Available from: http://www.mospi.nic.in/ mospi_new/upload/Children_in_India_2012.pdf [Last accessed on 2013 Dec 10].

13. Das S, Bapat U, More NS, Alcock G, Fernandez A, Osrin A. Nutritional status of young children in Mumbai slums: A follow-up anthropometric study. Nutr J 2012;11:100. Available from: http://www.nutritionj.com/ content/11/1/100 [Lsat accessed on 2013 Dec 12].

14. Sengupta P, Philip N, Benjamin Al. Epidemiological correlates of undernutrition in Under-5 years children in an Urban slum of Ludhiana. Health Popul Perspectlssues 2010;33:1-9.

15. Soumyajit M, Kausik C, Kazi AM, Ghosh D, Paul S. Stunting, under weight and overweight: A major health problem among children under 3 years of age in urban areas of West Bengal, India. Serbian J Exp Clin Res 2012;13:93-8.

16. Kaur G, Kang HS, Singal P, Singh SP. Nutritional status: Anthropometric perspective of preschool children. Anthropologist 2005;7:99-103.

17. Kamal AA, Bener A, Ahmed MA, Al- Mulla K. Growth pattern of Qatari preschool children. Public Health 2004;45:461-5. 
18. Rehman AR, Gladstone BP, Verghese VP, Muliyil J, Jaffar S, Kang G. Chronic growth faltering amongst a birth cohort of Indian children begins prior to weaning and is highly prevalent at three years of age. Nutr $\mathrm{J}$ 2009;8:44.

19. Dreze J, Sen A. An Uncertain glory, India and its Contradiction. Chapter 6. London: Penguin Books Ltd; 2013. p. 158-60.

20. Ramji S. Impact of infant \& young child feeding \& caring practices on nutritional status \& health. Indian J Med Res 2009;130:624-6.

21. Sule SS, Onayade AA, Abiona TC, Fatusi AO, Ojofeitimi EO, Esimai OA, et al. Impact of nutritional education on nutritional status of under-five children in two rural communities of south-west Nigeria. Niger Postgrad Med J 2009;16:115-25

22. Final Report and recommendations, Malnutrition Monitoring Committee. 2007-2012;6.

23. Raghav $\mathrm{PR}$, Rathod HK, Hazari K. Factors affecting anthropometric parameters of preschool children in urban slum. Pune: Indian Medical Gazette; 2010. p. 175-80.

24. Dhone AD, Chitnis UB, Bhawalkar JS, Jadhav SL. Epidemiological study of under nutrition among under five years children in an urban slum. Med J DY Patil Univ 2012;5:110-3.

25. Mittal A, Singh J, Ahluwalia SK. Effect of maternal factors on the nutritional status of 1-5 year old children in urban slum population. Indian J Community Med 2007;32:264-7.

26. Arya A, Devi R. Influence of maternal literacy on the nutritional status of preschool children. Indian J Pediatr 1991;58:265-8.

27. Gupta MC, Mehrotra M, Arora S, Saran M. Relation of childhood malnutrition to parental education and mothers' nutrition related KAP. Indian J Pediatr 1991;58:269-74.

How to cite this article: Mamulwar MS, Rathod HK, Jethani S, Dhone A, Bakshi T, Lanjewar B, et al. Nutritional status of underfive children in urban slums of Pune. Int $\mathrm{J}$ Med Public Health 2014:4:247-52.

Source of Support: Nil, Conflict of Interest: None declared. 